\title{
The Implementation Approach of Implicit Education in Ideological and Political Education
}

\author{
Weihong Cai \\ College of Marxism, University of Jinan \\ Jinan, Shandong Province, PRC \\ xiaobai417@sina.com
}

\begin{abstract}
Implicit education is an important direction of Ideological and political education reform and development, which helps to rectify the tendency of fossilization in ideological and political education o, improves the effectiveness of Ideological and political education. To meet th new requirements of ideological and political education in present situation, we must actively explore new ways and create a new situation ein ideological and political education. Compare to dominant education which is based on the course of Ideological and political theory , implicit education has unique features and advantages, which has great significance for full play of Ideological and political theory course and its reform.
\end{abstract}

Keywords - Implicit education ideological and political education in universities; Implementation approach

Ideological and political education is one of the most important part of college quality education, which plays a great role in the formation of colledge student's world outlook, views on life and values. The ideological and political theory course bears the task of systematic education of Marx's theory, shares the great responsibilities of "arming students with scientific theory, cultivating students with excellent culture", and is the main channel of ideological and political education of College students. But besides that, the students also experience a kind of Ideological and political education which is informal, latent, no or less premeditated and exists in the daily life -- the implicit education. Implicit education and dominant education which is based on Ideological and political theory course are the two basic modes of Ideological and political education in college, they have their own characteristics, functions, but are complementary. In the process of the implementation of the ideological and political education, one-sided emphasis on either side are biased, we should combine the two, in order to enhance the effectiveness of Ideological and political education, open up a new situation of Ideological and political education in universities.

\section{The CONNOTATION AND FEATURE OF IMPLiCiT EDUCA-} TION

\section{A. Connotation}

Implicit education research starts from the 60's of last century in foreign countries, different scholars have studied on its 1rospection from different 1rospective, can be described as different people, different views. One is not precise enough but more easy to understand is that implicit education is a manner and process which guides students to learn and gain experience education which is beneficial to their individual physical and mental health and personality development. It does not directly point to the subject content, no systematic subject norms, more belong to intangible spiritual culture, such as behavior norms, campus culture, teacher, school spirit and study style. Broadly speaking, it is everything students learned in school besides formal school courses.

\section{B. Features}

The features of implicit education are closely connected to its connotation. From the intuitive point of view, the greatest feature of the implicit education is its invisibility, whether its purpose, method, or effect. Therefore, some scholars of implicit education summed up its features as "the subjectivity, occult, prospective, non intelligent and non procedural", some other scholars describe its features as "optionality of education process, unpredictability of education results, openness of education methods, implicity of education content, autonomy of education subjects", and so on. These generalizations are reasonable, but the author thinks that besides this, the implicit education also have other deeper features:

Firstly, implicit education is not a force-feeding education. Force-feeding education in general is also called the "injection" education, it features that educators inculcate knowledge to students. Freire points out that the main method of force-feeding education is inculcation.This kind of method is to let students can only receive and memorize knowledge, students became a "container". The more knowledge teachers packed into the container, the better teachers they are. The more knowledge students can store, the better students they are. However, implicit education is not a force-feeding education, it is not plainly blunt preach, does not impose truth, viewpoint, requirements to the educatees, but infiltrate educational intention and purpose into related activities or circumstances. It is a kind of latent power, students receive education unconsciously, talk and not preach, let ideas with rich education significance leap into the educatees' heart quietly through some popular forms, which will settle down in their mind so as to reach sublimation or insight.

Secondly, implicit education is a kind of open education which shows in educational ideas, resources, methods and so on. From the educational idea point of view , implicit education emphasizes the development and future and sociality of education ,does not just teach knowledge and skills any more, but to fully develop the potential of each 
student, develop students' healthy personality, cultivate students' comprehensive quality, lets the student grow up comprehensively and coordinatively. From the educational resources point of view, no matter what type or form of education resources are, as long as they are endowed with certain educational experience, can play the role of implicit education, can constitute implicit education resources. From the educational methods point of view, implicit education should pay more attention to expansion of education which centered by school education to family and society and transformation of education which based on class education to practical education. So to speak, the openness and diversification of implicit education is consistent with the contemporary social progress and cultural evolution as well as the individual's free development.

\section{BASIC METHODS FOR THE IMPLEMENTATION OF IM- PLICIT EDUCATION}

In the process of implementation of the ideological and political education, to make full use of implicit education, it requires the participation of school, teacher and student. For teachers, the use of implicit education actually is the process of introducing implicit education resources into their teaching activities. Teachers must fully understand the great significance of effective implementation of implicit education to the reform of ideological and political theory course and improvement of the quality of ideological and political education and continuously work on effective methods for the implementation of implicit education.

\section{A. The Implicit Education in the Practice Experience}

The forms of social practical activities is varied, such as site visit, community survey, community services, cultural and sporting activities, etc. one of the basic metnods of implicit education is to pack the content of ideological and political education into activity through all these social practices. for example ,through red tourism and visiting old revolutionary base areas and history musem, students can receive the education of patriotism and revolutionary spirit and some other activities like raising-flag ceremony ,art performance, sports game, serving as a teacher in rural area,working in hinterland are all contain the content of ideological and political education. "The western developed countries attach great importance to practical education, universities in the United States, France and Japan, all offer students a variety of social practice program, formed the systemic mode for practical education, effectively make use of practical education as it plays the role of implicit education." [5], we can draw lessons from the experience of the western developed countries, base on China's national conditions, start all kinds of social practice, improve the 2 fecttiveness of ideological and political education.

\section{B. The Implicit Education Under the Edification of Envi- ronment}

According to Canadian scholar Stephen, "if there is something of real value for college students, it was the living environment around them". Both the natural and cultural environment of the campus plays important role in edifying students' sentiment and cultivating their good personality, and are also resources for implicit education. Campus environment and dominant education cooperate with each other, bring out the best in each other's effect, and is also helpful to improve the effect of college ideological and political education.

The natural environment of universities is the carrier of material implicit education which includes campus building, facilities and campus beautification, all of which exist as the carrier of school material culture. A school with its environment well built exudes strong cultural ambiance and great vitality, it reflects educators' the value orientation, interests, and literacy, is not only enjoyment of beauty for students, but also gives students edification and infection, profoundly affects students' moral character and their choice for behavior and lifestyle. Cultural environment is the carrier of spiritual implicit education including current school education policy, school orientation, curriculum content, teaching methods and so on. And it also includes the school's cultural tradition and pursuit for the future development of school. Campus cultural environment does not only reflect shallow cultural concept of the majority, but also their ideology which is recognized and followed by the most of teachers and students, therefore, directly impact the mental state of college students. Meanwhile, cultural spirit which is reflected by campus cultural environment has strong permeability, it soaks, lurks and diffuse in the whole campus environment factors and the main groups of campus, forms a kind of strong spirit atmosphere, giving the school ,teachers and students a unique charm.

\section{Implicit Education Contained in Cirruculum Design}

Usually we call school curriculum the dominant curriculum, also known as the regular curriculum or formal courses, which has a clear teaching purpose, well designed teaching plan in advance and carefully designed teaching methods. During implementation of dominant curriculum, students receive academic knowledge as expected at the same time also unconsciously get unacademic knowledge, according to Dewey's educational thoughts, while students complete their formal curriculum, they also "accidentally" win the idea, emotion, volition, interest, motivation, etc., these factors are all unexpected result for the curriculum's designer, so to speak, dominant curriculum accidently reach the purpose of implicit education. Therefore, from this point of view, dominant curriculum is an important carrier of implicit education, to infiltrate ideological and political education into every subjects is one of the most important method of implicit education. About the relation of subject teaching and ideological and political education, German educator Herbart has a famous saying: "Teaching without moral education is only a method without purpose; moral education without subject teaching is only a purpose without methods. In the process of colledge education, it's easy to find that those content of ideological and political education which mixed in related subject are more easy for students to accept, usually effect students' thought and sentiment subtly. 


\section{IMPLICIT EDUCATION IS OF GREAT SIGNIFICANCE FOR THE REFORM OF IDEOLOGICAL AND POLITICAL EDU- CATION IN UNIVERSITIES}

Dominant education which based on ideological and political theory course is the main form of ideological and political education method, plays an important role in ideological and political education. But everything has its shortcomings and merits, simply relying on dominant education which features in force-feeding is difficult to give full play to its function and achieve the desired effect, especially in the current situation, the college students' value orientation diversified increasingly, their subject consciousness, innovation consciousness and equality consciousness become stronger, the traditional way of ideological and political education obviously cannot meet the students' demands. $<<$ The central committee of the CCP, the state council's opinions on further strengthening and improving ideological and political education $>>$, points out: "on the basis of inheriting the party's fine tradition, o ideological and political education should actively explore new methods, reflects the feature of times ,grasp the regularity, be full of creativity, enhance effectiveness." To meet the new requirements of College students' ideological and political education, we must actively explore new way of ideological and political education in current new situation and be innovative.

First of all, the openness of the implicit education make its influence with large extensiveness, which meets the space and time that dominant education cannot reach, thus, play a complementary role to dominant education. In traditional ideological and political education, college students receive education on formal occasions, which is difficult to get enhanced and faces the danger of being weakened. The methods of implicit education infiltrate in all aspects of the campus, "from the space, including in and out of the campus, inside and outside the classroom, from the time point of view, including the system, lasting effect and accidental, temporary impact; look from the impact source itself, including visible substantive and invisible than substantive influence; from the extent of self- consciousness of the impact, including conscious, the man controlled influence and a more spontaneous." [7]The extensiveness of implicit education's can effectively change the phenomenon that ideological and political education always separate with their lives, makes up the short of dominant ideological and political education, makes the ideological and political education generate positive influence for colledge students in learning, living and entertainment.

Second, the implicitness of implicit education makes its content have better acceptability. Ideological and political theory class is a method of implicit education which is obvious, straight, and of strong purpose. It gives systemic education of ideological and political theory to colledge students, meanwhile, it tend to make students tired and even psychological inversion. Implicit education emphasizes a hidden, indirect method of education, its educational method is irregular, educational process is full of pleasure, is helpful to change the tendency of fossilization of ideological and political education, therefore, makes students re- ceive education unconsciously, as time goes by its effect becomes deeply ingrained, improves the effectiveness of ideological and political education and makes its effect more persistent.

Moreover, implicit education pay attention to the cultivation of college students' moral emotion and moral volition, can effectively promote the transformation from moral cognition to moral behavior, strengthen the function of dominant education. People's quality is the joint manifestation of cognitive and emotional qualities. Dominant education plays an important role in improving students' cognitive ability, but it only limited to the classroom and teaching material which may lead to one-sided development of students' cognitive factors and cut the internal connection between cognitive learning and emotion. Implicit ideological and political education uses its implicit and indirect methods to avoid force-feeding which may cause students' psychological inversion whose independent consciousness keep growing, pays attention to create vivid teaching situation for college students to nourish their minds and temper their willpower so as to build their character ,reach the internal unity of emotion, attitude, behavior and skills and lay the foundation for them to know the world, to participate in social activities, to adapt to the society, to be an qualified socialist citizen with the sense of caring, the sense of responsibility, good habits and personality.

\section{REFERENCES}

[1] The CPC Central Committee and State Council.On Further Strengthening and improving ideological and political education[C].Guangming Daily, October 15, 2004.

[2] Jia Keshui,Zhu Jianping,Zhang Rushan, The concepts definition and essence characteristic of implicit education[J],Educational Research, 2000,(8): 37-41.

[3] Shen Jiaqi.On Implicit education[J],Education Exploration.2002,(1):54-56.

[4] Pauio Freire.Pedagogy Of The Oppressed[M], Translated by Gu Jianxin,Shanghai:East China Normal University Press, 2001: 24

[5] Liu Xiaofang.The Implicit Education in The Ideological and Political Education of The Undergraduate[J],Contemporary Youth Research,2006,(6):16.

[6] Zheng Yongting, Methodology of Ideological and Political Education[M],Beijing:Higher Education Press, 1999,185.

[7] Qi Wanxue,Du Shizhong, The Modern Theory of Moral Education[M],Jinan:Shandong Education Press,1997:363. 